\title{
10 Preguntas a Martínez Zorrilla
}

Manuel Atienza

Pormotivos completamente ajenos a mi voluntad, no pude en su momento participar en la discusión de la excelente tesis de doctorado de David Martínez Zorrilla de la que trae causa este trabajo. Por ello, y porque se trata de un tema (los dilemas morales y el Derecho) del que yo me he ocupado en diversas ocasiones (aunque destacando aspectos del mismo distintos a los que más parecen interesar a M.Z.), no quiero dejar pasar ahora la ocasión que amablemente me brinda de comentar su nueva contribución. Lo haré en forma de 10 preguntas 
que la lectura de este interesante texto me ha suscitado.

1. Al comienzo de su trabajo, afirma M.Z. que "apenas se ha prestado atención al impacto o relevancia que los conflictos y dilemas morales pueden tener en el ámbito jurídico" (p. 18). ¿No está eso en contradicción con lo que dice más delante de que los dilemas morales ingresan en el ámbito jurídico a través de lo que él llama "conflictos constitucionales", cuando resulta que esos conflictos han de resolverse a través de la ponderación y que la ponderación es lo que podría llamarse un "tema estrella" en la teoría del Derecho desde hace bastantes años?

2. M.Z. dice partir de una noción puramente pragmática de conflicto normativo y no de una definición en términos lógicos (o sea, de la idea de que los conflictos normativos son inconsistencias lógicas). Ahora bien, la definición "afinada y precisada" que presenta a continuación, ¿tiene también un carácter simplemente pragmático, o está efectuada en términos lógicos? Yo diría que lo que M.Z. parece entender por "conflicto normativo" es un tipo de inconsistencia lógica, pero entonces: ¿cómo puede evitar el problema que le había llevado a preferir una noción puramente pragmática? Y, por cierto, ¿qué hay que entender por "noción puramente pragmática"?

3. En una nota a pié de página (la 21), M.Z. afirma que la ponderación no es el único instrumento para resolver los conflictos constitucionales, y plantea, como posible alternativa, la teoría coherentista de Susan Hurley. ¿Pero es realmente la coherencia una alternativa a la ponderación? ¿Es algo distinto a la idea de coherencia el criterio que los juristas manejan cuando dicen "ponderar" principios o valores?

4. En el apartado III (p.25) M.Z. critica a Alexy en estos términos: "Lo que en mi opinión es un error de Alexy es el pensar que existe una vinculación conceptual entre el establecimiento de 
relaciones de precedencia condicionada y el principio de proporcionalidad, cuando no existe impedimento conceptual alguno en imaginar algún mecanismo o criterio para el establecimiento de relaciones de precedencia condicionada basados en algo distinto a los grados de afectación o satisfacción de los elementos en conflicto”. ¿Pero en qué podría basarse entonces? $\mathrm{O}$, dicho de otra manera, ¿se aplicaría la crítica a quienes interpretaran -como, en mi opinión, lo hace Alexy- que "precedencia condicionada" quiere decir "precedencia condicionada justificada"?

5. Al final del apartado III, escribe M.Z.: "Dado que todos ellos [se refiere a conceptos como "derechos fundamentales", "dignidad humana", "integridad moral", etc.] forman parte de igual modo del texto constitucional y carecemos, en principio, de criterios estrictamente formales (como lex superior, etc.) para determinar una solución, parece que la alternativa más razonable es trasladar la cuestión al discurso moral, a fin de poder ofrecer también una respuesta a la controversia jurídica, que en su contenido tampoco difiere de manera destacable de una controversia moral”. Ahora bien, ¿por qué es "razonable" pensar que los criterios jurídicos tienen que ser “estrictamente formales”? ¿No hay aquí algo bastante parecido a una falacia: como no hay criterios jurídicos estrictamente formales, entonces no hay criterios jurídicos en absoluto?

6. En el apartado IV, M.Z. habla de dos sentidos de "obligación prima facie”. ¿Pero no cabría pensar que se trata más bien de un solo sentido, o sea, que es lo mismo decir que 1) alguien tiene en principio o a primera vista una obligación que luego, consideradas todas las circunstancias del caso, puede que no tenga, o bien que 2) alguien tiene una obligación que puede resultar derrotada? Lo que a M.Z. le permite mantener la distinción es que, en el primero de los sentidos, se hablaría de una obligación 
prima facie para referirse a una obligación "que resulta finalmente desechada o superada". ¿Pero es este, realmente, un uso habitual (según M.Z. el sentido "que predomina en la filosofía moral”) de la expresión? ¿No habría más bien que sustituir la frase de M.Z. por "que pueda resultar finalmente desechada o superada"? Yo veo bastante natural pensar (o hablar en términos de) que una obligación moral prima facie puede verse confirmada una vez consideradas todas las circunstancias: es más, es prácticamente una necesidad lógica en los casos de conflicto que se resuelven a favor de una de las obligaciones -de los principios o valoresenfrentados (por ejemplo, la obligación prima facie de respetar el derecho al honor de las personas se convierte en obligación definitiva si se piensa que, dadas las circunstancias, las razones a favor de ese principio pesaban más que las favorables a la libertad de expresión o de información).

7. En la definición de "obligación moral” que M.Z. toma de M.J. Zimmerman, ¿qué hay que entender por "deónticamente inferior" o, en general, por "valor deóntico”? ¿Es algo distinto a, respectivamente, "peor" y "bueno”? ¿Se trata entonces de identificar los conceptos normativos y los valorativos, lo debido y lo bueno? ¿Sería aceptable esa identificación?

8. M.Z. distingue dos posibles situaciones dilemáticas: cuando hay equivalencia (entre las obligaciones) o cuando hay incomparabilidad. ¿Pero son realmente dos, cuando resulta que la respuesta en ambos casos es la misma (y M.Z. presenta el ejemplo que maneja de "incomparabilidad" como un caso de "empate": dos candidatos a una plaza empatados en cuanto a sus méritos)? Y, si en ambos casos lo que resulta es que está permitido realizar cualquiera de las dos acciones, ¿habría que concluir que, en realidad, para M.Z., no hay situaciones de dilema moral?

9. ¿Por qué piensa M.Z. que, en la moral, el "azar" resulta un procedimiento de toma de decisión más aceptable que 
en el Derecho? ¿No sería más razonable aceptar que en la moral (en contra de lo que él parece sostener) los números sí que cuentan?

10. ¿Por qué pensar que la dimensión institucional del Derecho se traduce exclusivamente en la existencia de reglas (o sea, justifica la existencia de una regla "a sabiendas" de que no es mejor que otra)? ¿No parece más razonable pensar que la dimensión institucional del Derecho genera o justifica principios (como el de seguridad jurídica) que habría que ponderar con otros principios (por ejemplo, con otros principios sustantivos, como el de justicia)? Y finalmente, y por más que M.Z. dice interesarse sobre todo por las cuestiones conceptuales y no tanto por las de carácter práctico, ¿no podría ocurrir que en este caso las cuestiones conceptuales y las de carácter práctico se imbrican entre sí de tal manera que no es posible separarlas en el análisis (lo que, me parece, termina por ocurrir en su trabajo)? ¿Tiene algún interés plantearse el concepto de "dilema moral" en el Derecho (yo lo he llamado “caso trágico"), si no es para ver si realmente existen esas situaciones y ( $s i$ la respuesta a la primera pregunta fuese afirmativa) por qué existen y qué cabe hacer al respecto? 